\title{
The clinical benefit of pegylated liposomal doxorubicin in patients with metastatic breast cancer previously treated with conventional anthracyclines: a multicentre phase II trial
}

\author{
S-E Al-Batran*, , J Bischoff ${ }^{2}$, G von Minckwitz ${ }^{3}$, A Atmaca', U Kleeberg ${ }^{4}$, I Meuthen ${ }^{5}$, G Morack ${ }^{6}$, W Lerbs $^{7}$, \\ D Hecker ${ }^{7}, J_{\text {Sehouli }}^{8}$, A Knuth ${ }^{9}$ and E Jager ${ }^{1}$ \\ 'Department of Hematology and Oncology, Krankenhaus Nordwest, 60488 Frankfurt am Main, Frankfurt, Germany; ${ }^{2}$ Klinik Bad Trissl, Oberaudorf, \\ Germany; ${ }^{3}$ Universitats-Frauenklinik/German BreastGroup, Frankfurt, Germany; ${ }^{4}$ Hämatologisch-Onkologische Praxis Altona, Hamburg, Germany; \\ ${ }^{5}$ Krankenhaus Holweide, Köln, Germany; ${ }^{6}$ Klinikum Berlin-Buch, Berlin, Germany; ${ }^{7}$ Essex pharma, München, Germany; ${ }^{8}$ Frauenklinik Charité Campus \\ Mitte, Berlin, Germany; ${ }^{9}$ Universitätsspital Zürich, Zürich, Switzerland
}

\begin{abstract}
This study evaluates the clinical benefit of pegylated liposomal doxorubicin (PLD) in patients with metastatic breast cancer (MBC), previously treated with conventional anthracyclines. Seventy-nine women with MBC previously treated with anthracyclines received PLD $50 \mathrm{mg} \mathrm{m}^{-2}$ every 4 weeks. All patients were previously treated with chemotherapy and $30 \%$ of patients had $\geqslant 3$ prior chemotherapies for metastatic disease. Patients were considered anthracycline resistant when they had disease progression on anthracycline therapy for MBC or within 6 months of adjuvant therapy. The overall clinical benefit rate (objective response + stable disease $\geqslant 24$ weeks) was $24 \%$ (16.1\% in patients with documented anthracycline resistance vs $29 \%$ in patients classified as having non-anthracycline-resistant disease). There was no difference with respect to the clinical benefit between patients who received PLD $>12$ months and those who received PLD $\leqslant 12$ months since last anthracycline treatment for metastatic disease (clinical benefit 25 vs $24.1 \%$, respectively). Median time to progression and overall survival were 3.6 and 12.3 months, respectively. The median duration of response was 12 months, and the median time to progression in patients with stable disease (any) was 9.5 months. Fourteen patients (17.7\%) had a prolonged clinical benefit lasting $\geqslant 12$ months. In conclusion, PLD was associated with an evident clinical benefit in anthracycline-pretreated patients with MBC.
\end{abstract}

British Journal of Cancer (2006) 94, I6I5-1620. doi:10.1038/sj.bjc.6603 I 58 www.bjcancer.com

Published online 9 May 2006

(c) 2006 Cancer Research UK

Keywords: liposomal doxorubicin; breast cancer; anthracycline pretreated

The treatment of patients with metastatic breast cancer (MBC), who failed one or more previous chemotherapy regimens, and whose favourable performance status justifies further treatment, represents a significant challenge to the oncologist. In patients with $\mathrm{MBC}$, anthracyclines and taxanes are the most active drugs. However, the majority of pretreated patients with MBC had been exposed to anthracycline- and taxane-based therapies either in the adjuvant or in the metastatic setting. Here, the repeated use of conventional anthracyclines is limited by cumulative cardiac toxicity and myelosuppression, despite long anthracycline-free intervals in many patients (Singal and Iliskovic, 1998; Pai and Nahata, 2000). In these cases, pegylated liposomal doxorubicin (PLD) may represent an attractive option. Pegylated liposomal doxorubicin has demonstrated comparable efficacy to doxorubicin with a favourable toxicity profile (Gabizon and Martin, 1997; Ranson et al, 1997; Lyass et al, 2000; Symon et al, 2000; Gabizon et al, 2003; O'Shaughnessy, 2003; Theodoulou and Hudis, 2004). It was associated with less alopecia, myelotoxicity, and cardiac

*Correspondence: Dr S-E Al-Batran; E-mail: albatran@aol.com Received 30 January 2006; revised 6 April 2006; accepted 6 April 2006; published online 9 May 2006 toxicity than free doxorubicin but higher rates of palmar-plantar erythrodysesthesia (PPE) and mucositis (O'Brien et al, 2004). Preclinical and clinical studies have indicated that PLD may not be completely cross-resistant with conventional anthracyclines (Gabizon et al, 2003; O'Brien et al, 2004). Based on these results, we believe that there is a rational basis for the use of PLD as a second-, third-, or fourth-line therapy in patients with MBC after anthracycline and/or taxane failure. However, in fact, there have been no clinical studies evaluating its clinical benefit in this setting. The present study evaluates the clinical benefit of PLD in an anthracycline-pretreated population and attempts to identify the patients who are more likely to benefit from the treatment.

\section{PATIENTS AND METHODS}

\section{Patient eligibility}

Female patients were eligible with histologically confirmed $\mathrm{MBC}$ with at least one measurable lesion, at least one prior chemotherapy for metastatic disease, Karnofsky performance status $\geqslant 70 \%$, age $>18$ years, life expectancy $\geqslant 3$ months, no concurrent uncontrolled medical illness, no other malignancies (with the exception of squamous cell carcinoma of the skin treated by 
surgery), baseline left ventricular ejection fraction (LVEF) $>50 \%$, and sufficient hepatic and bone marrow function. Number, type, and cumulative dose of previous chemotherapy were not limited. Patients were excluded from the study if they had cardiac diseases including congestive heart failure, atrial or ventricular arrhythmia, were pregnant or breast-feeding. Women with child-bearing potential were advised to take adequate precautions to prevent pregnancy. Participants gave written informed consent before they entered the study, which was approved by the Ethics Committees responsible for the participating centers.

\section{Chemotherapy}

The initial infusion duration of PLD $50 \mathrm{mg} \mathrm{m}^{-2}$ was $1 \mathrm{~h}$ in order to minimise the risk of infusion-related reactions. Subsequent doses were given as a 30-min infusion. Cycles were repeated every 4 weeks and treatment was continued until disease progression, unacceptable toxicity, patient's refusal, or physician's decision. Antiemetic prophylaxis was given according to local protocols. All patients received vitamin $\mathrm{B}_{6}$ (Pyridoxine) $300 \mathrm{mg}$ orally once daily after breakfast during the treatment to prevent PPE (Nagore et al, 2000).

\section{Toxicity assessment}

Toxicity was graded according to the National Cancer Institute Common Toxicity Criteria (NCI-CTC) version 2. Cardiac toxicity was based on echocardiographic LVEF measurements and a 12-lead electrocardiogram that were performed at baseline and every 8 weeks. Dose modifications of PLD were permitted for haematological toxicity, increases in total bilirubin, cardiac toxicity, PPE, mucositis, and other NCI-CTC grade 3 or 4 events.

\section{Assessment of response}

Responses were classified according to World Health Organization (WHO) criteria. Computed tomography (CT) scans of measurable lesions were carried out within 4 weeks before the start of the treatment and were repeated every two cycles. Responses were to be confirmed by subsequent CT scans $4-8$ weeks after the initial response documentation. Patients who discontinued the study were evaluated at least every 3 months. Patients were considered assessable for response if they had early disease progression or had received at least two cycles of treatment with at least one tumor assessment.

\section{Definitions and statistical analyses}

The primary end point of the study was clinical benefit defined as the rate of $\mathrm{CR}+\mathrm{PR}+\mathrm{SD} \geqslant 6$ months duration. The treatment was considered active if the clinical benefit rate exceeded $33 \%$. Conversely, the treatment was considered inactive if the clinical benefit rate was below $20 \%$. Based on this hypothesis, the inclusion of 100 patients was planned and considered appropriate to generate robust results. Response and toxicity were analysed descriptively. The $95 \%$ confidence interval (CI) for response and clinical benefit was calculated. The progression-free survival (PFS) was measured from the start of the treatment until progression or death of any cause. The overall survival (OS) was measured from the start of the treatment until death of any cause. Anthracycline resistance was defined as having disease progression on anthracycline-based therapy for MBC or within 6 months of adjuvant anthracycline-based therapy.

\section{RESULTS}

Between May 2000 and October 2001, 100 female patients with MBC were enrolled in the study at 25 German centres. First patient
Table I Patient characteristics

\begin{tabular}{|c|c|c|}
\hline Patient characteristics & $\begin{array}{l}\text { No. of patients } \\
\quad(n=79)\end{array}$ & $\%$ \\
\hline \multicolumn{3}{|l|}{ Age (years) } \\
\hline Median & 58 & \\
\hline Range & $35-79$ & \\
\hline \multicolumn{3}{|l|}{ Karnofsky performance status (\%) } \\
\hline 100 & 18 & 22.7 \\
\hline 90 & 27 & 34.1 \\
\hline$\leqslant 80$ & 34 & 43.2 \\
\hline \multicolumn{3}{|l|}{ No. of metastatic sites } \\
\hline 1 & 26 & 32.9 \\
\hline 2 & 25 & 31.6 \\
\hline$\geqslant 3$ & 28 & 35.4 \\
\hline Oestrogen and/or progesterone receptor positive & 68 & 86.0 \\
\hline HER2 positive & 4 & 5.1 \\
\hline \multicolumn{3}{|l|}{ Site of disease } \\
\hline Bone only & 5 & 6.3 \\
\hline Non-visceral soft tissue only & 9 & $\mid 1.1$ \\
\hline Visceral & 65 & 82.6 \\
\hline
\end{tabular}

${ }^{a}=3+$ by immunohistochemistry or amplification by fluorescence in situ hybridization.

was included on 25 May 2000 and last patient on 15 October 2001. Seventy-nine of 100 patients were previously treated with anthracyclines. In order to create a more homogeneous patient population, the analysis was confined to the group of patients previously treated with anthracyclines $(n=79)$. The median age of patients was 58 years (range 35-79 years) and the median Karnofsky performance status was 90 (range 60-100). Most patients $(82.6 \%)$ had visceral disease. All patients were pretreated with at least one chemotherapy regimen in the metastatic setting and all had received prior anthracycline chemotherapy. Seventyseven per cent of the patients had received prior anthracyclines for metastatic disease. The anthracycline-free interval was $\leqslant 12$ months in $41.8 \%$ of the patients. Patient characteristics and treatment history are listed in Tables 1 and 2. All patients were evaluable for safety and efficacy.

\section{Safety}

Seventy-nine patients received a total of 325 treatment cycles. The median number of cycles was 3 (range 1-12 cycles). The median cumulative dose of PLD was $150 \mathrm{mg} \mathrm{m}^{-2}$ (range $50-580 \mathrm{mg} \mathrm{m}^{-2}$ ). A dose reduction was required in 12 of 79 patients (15.1\%). Nine patients discontinued treatment because of adverse events possibly related to the study treatment: two for PPE, two for stomatitis, one for prolonged haematological toxicity (thrombocytopenia and neutropenia), and one each for skin reactions other than PPE, allergic reaction, circulatory collapse, and bronchopneumonia. Four out of these nine patients received more than two cycles of treatment (three, three, five, and six cycles). No treatment interruptions or discontinuation for cardiac toxicity and no treatment-related deaths were reported.

Main toxicities are listed in Table 3. Neutropenia (17.1\%) and leukopenia (14.4\%) were the most frequent NCI-CTC grade 3-4 haematological toxicities. Among the non-haematological adverse events, NCI-CTC grade 3-4 stomatitis $(10.2 \%)$ was the most prominent. National Cancer Institute-CTC grade 3-4 PPE occurred in five patients $(6.4 \%)$.

Abnormal electrocardiograms during the treatment were documented in four patients who had normal baseline electrocardiograms. Electrocardiographic changes included tachycardia 
and tachyarrhythmia that were considered related to the progression of underlying disease. A decrease of LVEF $\geqslant 15 \%$ from baseline was not observed.

Table 2 Treatment history

\begin{tabular}{|c|c|c|}
\hline & $\begin{array}{l}\text { No. of patients } \\
\quad(n=79)\end{array}$ & $\%$ \\
\hline Surgery & 79 & 100.0 \\
\hline Adjuvant radiation therapy & 58 & 73.4 \\
\hline Hormonal therapy ${ }^{\mathrm{a}}$ & 68 & 86.0 \\
\hline Previous adjuvant chemotherapy & 44 & 55.6 \\
\hline \multicolumn{3}{|l|}{ Previous chemotherapy for $M B C$} \\
\hline I regimen & 30 & 37.9 \\
\hline 2 regimens & 23 & 29.1 \\
\hline$\geqslant 3$ regimens & 26 & 32.9 \\
\hline Previous anthracycline-based chemotherapy & 79 & 100.0 \\
\hline Adjuvant only & 18 & 22.8 \\
\hline Metastatic only & 54 & 68.4 \\
\hline Both settings & 7 & 8.9 \\
\hline \multicolumn{3}{|l|}{ Anthracycline-free interval (months) } \\
\hline $0-12$ & 33 & 41.8 \\
\hline$>12$ & 46 & 58.2 \\
\hline \multicolumn{3}{|l|}{ Dose of previous anthracycline-based chemotherapy ${ }^{b}$} \\
\hline Epirubicin (median, $360 \mathrm{mg} \mathrm{m}^{-2}$; range $140-8 \mid 0$ ) & 56 & 70.9 \\
\hline Mitoxantrone (median, $90 \mathrm{mg} \mathrm{m}^{-2}$; range $12-132$ ) & 11 & 13.9 \\
\hline Doxorubicin (median, $300 \mathrm{mg} \mathrm{m}^{-2}$; range $105-400$ ) & 8 & 10.1 \\
\hline Previous taxane-based chemotherapy & 54 & 68.4 \\
\hline Adjuvant only & 3 & $5.6^{\mathrm{c}}$ \\
\hline Metastatic only & 51 & $94.4^{c}$ \\
\hline Both settings & 0 & 0 \\
\hline \multicolumn{3}{|l|}{ Taxane-free interval (months) } \\
\hline $0-12$ & 39 & $72.2^{c}$ \\
\hline$>12$ & 15 & $27.8^{c}$ \\
\hline
\end{tabular}

$\mathrm{MBC}=$ metastatic breast cancer. ${ }^{\mathrm{a} A d j u v a n t}$ and/or metastatic. ${ }^{\mathrm{b}} \mathrm{Six}$ patients received an unknown cumulative dose of anthracyclines; two patients received epirubicin and mitoxantrone. In percentage of taxane-pretreated patients, $n=54$.

Table 3 Toxicities according to National Cancer Institute common toxicity criteria version 2.0

\begin{tabular}{|c|c|c|c|}
\hline & $\begin{array}{c}\text { Grade I-2 } \\
\quad(n=79)\end{array}$ & $\begin{array}{c}\text { Grade } 3-4 \\
(n=79)\end{array}$ & $\begin{array}{c}\text { All grades } \\
(n=79)\end{array}$ \\
\hline Toxicities & $n(\%)$ & $n(\%)$ & $n(\%)$ \\
\hline \multicolumn{4}{|l|}{ Nonhaematologic } \\
\hline Alopecia & $42(53.8)^{a}$ & & $42(53.8)$ \\
\hline Nausea & $33(42.3)$ & $4(5.1)$ & $37(47.4)$ \\
\hline Diarrhoea & $12(15.3)$ & 0 & $12(15.3)$ \\
\hline Vomiting & $25(32.0)$ & $2(2.5)$ & $27(34.6)$ \\
\hline Constipation & $24(30.7)$ & $3(3.8)$ & $27(34.6)$ \\
\hline Fever & $15(19.2)$ & 0 & $15(19.2)$ \\
\hline Infection & $16(20.5)$ & $6(7.6)$ & $22(28.2)$ \\
\hline Neurosensory & $23(29.4)$ & $2(2.5)$ & $25(32.0)$ \\
\hline PPE & $31(39.7)$ & $5(6.4)$ & $36(46.1)$ \\
\hline Mucositis & $26(33.3)$ & $8(10.2)$ & $34(43.5)$ \\
\hline \multicolumn{4}{|l|}{ Haematologic $(n=76)$} \\
\hline Neutropenia & $25(32.8)$ & $13(17.1)$ & $38(50.0)$ \\
\hline Leukopenia & $44(57.8)$ & II (I 4.4$)$ & $55(72.3)$ \\
\hline Anemia & $60(78.9)$ & $7(9.2)$ & $67(88.1)$ \\
\hline Thrombocytopenia & $23(30.2)$ & $3(3.9)$ & $26(34.2)$ \\
\hline
\end{tabular}

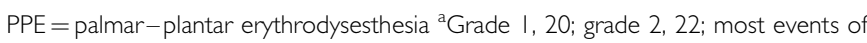
alopecia were considered not related to PLD but to prior therapies by the investigator.

\section{Tumor response and clinical benefit}

One complete response in 79 evaluable patients $(1,3 \%)$ and nine (11.4\%) partial responses were observed, adding to an overall response rate of $12.7 \%$ (95\% CI 4.7-20.6\%). Twenty-two patients (27.8\%; 95\% CI 17.3-38.4\%) had stable disease and 47 patients $(59.5 \%)$ had progressive disease. Patients with responses or stable diseases of $\geqslant 6$ months duration were considered for clinical benefit, resulting in an overall clinical benefit rate of $24 \%$ (95\% CI $14.6-33.4 \%)$. Patients with less exposure to prior chemotherapy regimens tended to have higher rates of clinical benefit (Table 4). In addition, higher rates of clinical benefit were achieved in taxane naive patients $\left(\chi^{2}, P=0.024\right.$; Table 5$)$. The clinical benefit was $16.1 \%$ in patients classified as having anthracycline-resistant disease vs $29 \%$ in non-anthracycline-resistant patients $\left(\chi^{2}\right.$, $P=0.186$; Table 5). There was no significant difference with respect to the clinical benefit between patients who received PLD $>12$ months and those who received PLD $\leqslant 12$ months since last anthracycline treatment for metastatic disease (clinical benefit 25 vs $24.1 \%$, respectively). Fourteen (17.7\%) patients experienced prolonged responses (response or stable disease) lasting $\geqslant 12$ months. Eight $(57.1 \%)$ of these patients had an anthracycline-free interval $>12$ months, nine (64.2\%) were classified as having nonanthracycline-resistant disease, and seven (50\%) were taxane naive, resulting in no remarkable differences when compared with the full patient population.

\section{PFS and OS}

Patients were included in the survival analysis on an intent-to-treat basis. The median follow-up time was 30 months (range 1-47). Median PFS and OS for the entire group were 3.6 months (95\% CI

Table 4 The clinical benefit by the number of prior chemotherapies for $\mathrm{MBC}$

Clinical benefit $\geqslant 6$ months $^{\mathrm{a}}$

No. of previous chemotherapies for
MBC

\section{MBC}

All assessable pts, $n=79$

I regimen, $n=30$ pts

2 regimens, $n=23$ pts

$\geqslant 3$ regimens, $n=26$ pts

\begin{tabular}{rr}
19 & 24.0 \\
9 & 30.0 \\
5 & 21.7 \\
5 & 19.2 \\
\hline
\end{tabular}

$\mathrm{MBC}=$ metastatic breast cancer; pts = patients. ${ }^{\mathrm{a}}$ Defined as patients having an objective response of a stable disease of $\geqslant 6$ months duration.

Table 5 The clinical benefit by previous anthracycline and taxane treatment

Clinical benefit $\geqslant 6$ months ${ }^{a}$

Number of previous chemotherapies for MBC

No taxane, $n=25$ pts

Taxane, $n=54$ pts

Anthracycline-resistant, $n=31$ pts $^{b}$

Non-anthracycline-resistant, $n=48$ pts

\begin{tabular}{rc}
\hline & \\
\hline 10 & $\%$ \\
9 & 40.0 \\
5 & 16.6 \\
14 & 16.1 \\
& 29.1 \\
7 & \\
8 & 24.1 \\
\hline
\end{tabular}

Anthracycline-free intervalc

$0-12, n=29$ pts

$>12, n=32$ pts

25.0

$\mathrm{MBC}=$ metastatic breast cancer; pts $=$ patients. ${ }^{a}$ Defined as patients having an objective response or a stable disease of $\geqslant 6$ months duration. ${ }^{b}$ Defined as having disease progression on anthracycline-based therapy for MBC or within 6 months of adjuvant anthracycline-based therapy. ${ }^{C}$ Metastatic only. 


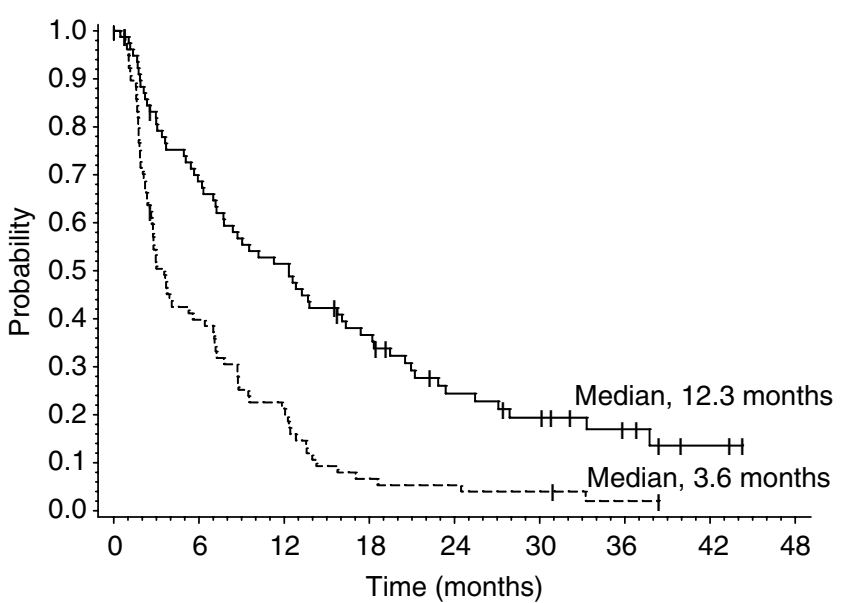

Patients at risk ( $\mathrm{I}=$ censored subject)

$\begin{array}{lrrrrrrrr}\text { OS - } 79 & 52 & 39 & 26 & 15 & 11 & 6 & 2 & 0 \\ \text { PFS - } 79 & 30 & 16 & 5 & 4 & 3 & 1 & 0 & 0\end{array}$

Figure I Overall survival and PFS survival for the entire group.

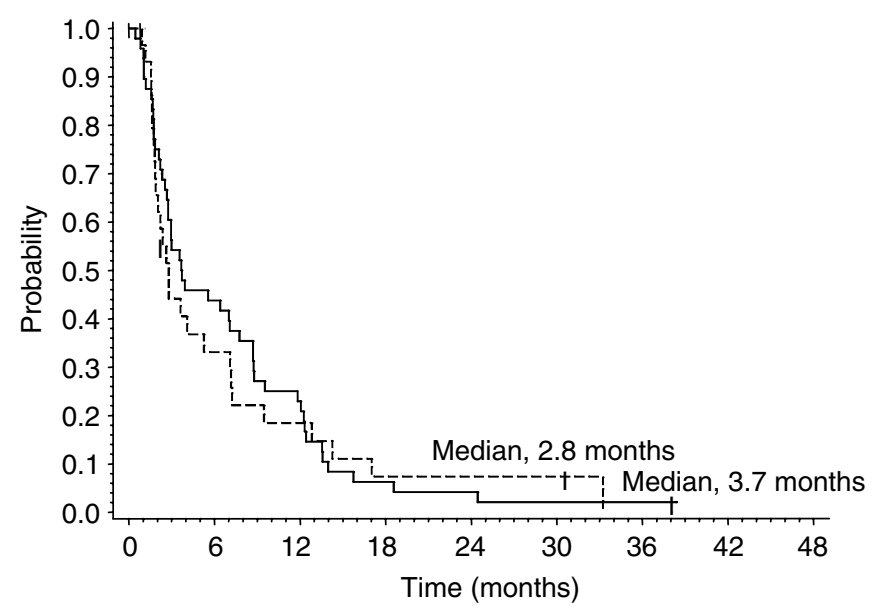

Patients at risk $(\mathrm{I}=$ censored subject $)$

$\begin{array}{lrccccccc}\mathrm{NR}-48 & 21 & 11 & 3 & 2 & 1 & 1 & 0 & 0 \\ \mathrm{R}=31 & 9 & 5 & 2 & 2 & 2 & 0 & 0 & 0\end{array}$

Figure 2 Progression free survival for patients with anthracycline resistance (R) vs those considered having anthracycline non-resistant disease (NR).

2.7-6.4) and 12.3 months (95\% CI 7.7-16.3), respectively. The response duration ranged from 7.0 to 24.5 months (median 12.0 months; 95\% CI 8.7-14.0), and the median PFS in patients with stable disease (any) was 9.5 months (95\% CI 7.8-13.6). Median PFS and OS were 2.8 (95\% CI 1.9-7.1) and 9.0 months (95\% CI 5.7-19.5), respectively, for patients classified as having anthracycline-resistant disease $v s 3.7$ (95\% CI $2.8-7.8)$ and 12.5 (95\% CI 7.8-18.2) months, respectively, for patients classified as having non-anthracycline-resistant disease. Progression-free survival and OS were assessed by the Kaplan-Meier analysis shown in Figures 1-3.

\section{DISCUSSION}

We report here the results of a phase II trial on PLD in patients with MBC previously treated with conventional anthracyclines. The study evaluates the clinical benefit of PLD in patients who had

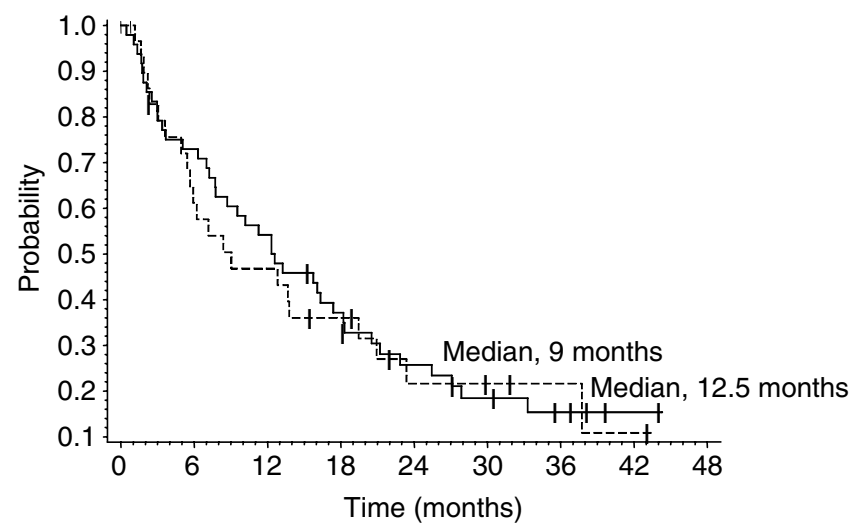

Patients at risk ( $\mathrm{I}=$ censored subject)

$\begin{array}{llccccccc}\mathrm{NR}-48 & 35 & 26 & 17 & 11 & 7 & 4 & 1 & 0 \\ \mathrm{R}--31 & 17 & 13 & 9 & 4 & 4 & 2 & 1 & 0\end{array}$

Figure 3 Overall survival for patients with anthracycline resistance (R) vs those considered having anthracycline non-resistant disease (NR).

received multiple prior chemotherapies including anthracyclines and taxanes. All the patients analysed in our study had received prior anthracycline therapy, and $68 \%$ of the patients had received prior taxane therapy. Moreover, $33 \%$ of the patients received the study treatment in the greater than or equal to fourth-line setting, and most had visceral disease. In this patient population, an overall clinical benefit rate of $24 \%$ was achieved. The median response duration was 12 months, and the median PFS in patients with stable disease (any) was 9.5 months. The overall clinical benefit observed in our study, must, therefore be considered as modest but evident (Clinical Benefit rate $<33 \%$ but $>20 \%$ ). Notably, once a response or a stable disease was achieved, it was durable.

The clinical benefit was highest in patients with no prior exposure to taxanes and lowest - but still evident - in patients with documented anthracycline resistance. There was, on the other hand, no significant difference with respect to the clinical benefit between patients who received PLD $>12$ months and those who received PLD $\leqslant 12$ months since last prior anthracycline-based treatment for metastatic disease (clinical benefit 25 vs $24.1 \%$, respectively). These findings may indicate that the time that had passed since last anthracycline treatment ( $>12$ or $<12$ months) may not be a predictor of PLD efficacy, but the fact, whether patient's disease progressed on a prior anthracycline treatment or not. In general, our results are consistent with observations made by Keller et al (2004) in a recent phase III study with PLD vs vinorelbine in patients with taxane-refractory advanced breast cancer (response rate, median PFS, and OS, 12.7\%, 3.6 months, and 12.3 months, respectively, as compared with $10 \%, 2.9$ months, and 11 months, respectively). In this study, PLD was superior to vinorelbine in patients with taxane-refractory $M B C$ who had no prior exposure to an anthracycline and as effective as vinorelbine in patients with anthracycline-resistant disease, demonstrating activity in this group of patients. In this study, however, in contrast to our results, there were no differences in PFS and OS between patients with prior anthracycline exposure and patients with documented anthracycline resistance (median PFS, 2.4 vs 2.6 months and median OS, 9.2 vs 8.0 months, respectively), and the clinical benefit was not provided.

Capecitabine is a commonly used salvage regimen in anthracycline- and taxane-pretreated patients. Blum et al (2001) treated 162 patients who had received prior paclitaxel and anthracyclines with capecitabine. Median PFS, response duration, and OS were 3.1, 8.0, and 12.8 months, respectively. In a recent phase III study, Miller et al (2005) randomly assigned 462 women (15\% previously 
untreated, $46 \%$ previously treated with one, and $34 \%$ with two chemotherapies) with $\mathrm{MBC}$ to receive capecitabine alone or in combination with Bevacizumab. The objective response rate in the capecitabine group was $9.1 \%$. Median PFS, duration of response, and OS were 4.2, 7.6 (5 months for the combination group), and 14.5 months, respectively, and bevacizumab did not improve PFS or OS. Notably, a significant proportion $(15 \%)$ of the patients in this study represented previously untreated women who were more likely to respond to treatment. The rate of taxane-pretreated patients in our study was slightly lower than in the later study (64 vs $85 \%$ ), but our patients had received more previous therapies. Therefore, even though there are limitations to cross-study comparisons, one may conclude that the activity of PLD in previously treated patients with $\mathrm{MBC}$ seems to be similar to that of capecitabine. Generally, the efficacy of currently available drugs in this situation must be considered as low. The use of an ineffective drug for patients with previously treated MBC in two recent phase II studies resulted in a clinical benefit rate of 4.9 and $1.7 \%$, respectively (Albain et al, 2002; Von Minckwitz et al, 2005). Therefore, the $24 \%$ clinical benefit rate observed here, although modest, can be related to the treatment with PLD. In our study, PLD was generally well tolerated and the safety profile observed

\section{REFERENCES}

Albain K, Elledge R, Gradishar WJ, Hayes DF, Rowinsky E, Hudis C, Pusztai L, Tripathy D, Modi S, Rubi S (2002) Open-label phase II, multicenter trial of ZD1839 ('Iressa') in patients with advanced breast cancer. Breast Cancer Res Treat 76: S33, (abstract 20)

Blum JL, Dieras V, Lo Russo PM, Horton J, Rutman O, Buzdar A, Osterwalder B (2001) Multicenter, Phase II study of capecitabine in taxane-pretreated metastatic breast carcinoma patients. Cancer 92: $1759-1768$

Gabizon A, Martin F (1997) Polyethylene glycol-coated (pegylated) liposomal doxorubicin: rationale for use in solid tumours. Drugs 54: $15-21$

Gabizon A, Shmeeda H, Barenholz Y (2003) Pharmacokinetics of pegylated liposomal doxorubicin: review of animal and human studies. Clin Pharmacokinet 42: 419-436

Keller AM, Mennel RG, Georgoulias VA, Nabholtz JM, Erazo A, Lluch A, Vogel CL, Kaufmann M, von Minckwitz G, Henderson IC, Mellars L, Alland L, Tendler C (2004) Randomized phase III trial of pegylated liposomal doxorubicin $v s$ vinorelbine or mitomycin $\mathrm{C}$ plus vinblastine in women with taxane-refractory advanced breast cancer. J Clin Oncol 22: $3893-3901$

Lyass O, Uziely B, Ben-Yosef R, Tzemach D, Heshing NI, Lotem M, Brufman G, Gabizon A (2000) Correlation of toxicity with pharmacokinetics of pegylated liposomal doxorubicin (Doxil) in metastatic breast carcinoma. Cancer 89: 1037-1049

Miller KD, Chap LI, Holmes FA, Cobleigh MA, Marcom PK, Fehrenbacher L, Dickler M, Overmoyer BA, Reimann JD, Sing AP, Langmuir V, Rugo HS (2005) Randomized phase III trial of capecitabine compared with bevacizumab plus capecitabine in patients with previously treated metastatic breast cancer. J Clin Oncol 23: $792-799$

\section{Appendix}

\section{Participating institutions and investigators include the following}

Klinik Bad Trissl, Oberaudorf, Germany (Klaus Gutschow, MD; Joachim Bischoff, MD); Krankenhaus Nordwest, Frankfurt, Germany (Elke Jäger, MD; Salah-Eddin Al-Batran, MD); UniversitätsFrauenklinik Frankfurt, Frankfurt, Germany (Manfred Kaufmann MD, Gunter von Minckwitz, MD); Hämatologisch-Onkologische Praxis Altona, Hamburg, Germany (Ulrich R. Kleeberg, MD); Krankenhaus Holweide, Köln, Germany (Ingo Meuthen, MD); Klinikum Berlin-Buch, Berlin, Germany (Günter Morack, MD); here was consistent with that observed in earlier studies using PLD at $50 \mathrm{mg} \mathrm{m}^{-2}$ every 4 weeks (Nagore et al, 2000; O'Brien et al, 2004). No cardiac toxicities were seen and no significant changes in electrocardiograms or echocardiograms were observed during the study. Therefore, cardiac monitoring every other cycle may not be necessary, at least for patients receiving total doses of anthracyclines that are comparable to those applied in our study. In conclusion, our results indicate that the use of PLD is associated with an evident clinical benefit in patients previously treated with conventional anthracyclines. This clinical benefit is highest in patients with less exposure to prior chemotherapy regimens and taxane naive patients, and lowest in patients with documented anthracycline resistance.

\section{ACKNOWLEDGEMENTS}

We thank Dipl.-Stat. Michael Scholz (Trium Analysis Online $\mathrm{GmbH}$ ) for the statistical analysis. We thank Karin Scheffler (medical trial consulting + advice) for her assistance in data management and preparing the manuscript.
Nagore E, Insa A, Sanmartin O (2000) Antineoplastic therapy-induced palmar plantar erythrodysesthesia ('hand-foot') syndrome. Incidence, recognition and management. Am J Clin Dermatol 1: 225-234

O'Brien ME, Wigler N, Inbar M, Rosso R, Grischke E, Santoro A, Catane R, Kieback DG, Tomczak P, Ackland SP, Orlandi F, Mellars L, Alland L, Tendler C (2004) Reduced cardiotoxicity and comparable efficacy in a phase III trial of pegylated liposomal doxorubicin $\mathrm{HCl}$ (CAELYX ${ }^{\mathrm{TM}}$ / Doxil $^{\mathbb{R}}$ ) vs conventional doxorubicin for first-line treatment of metastatic breast cancer. Ann Oncol 15: $440-449$

O'Shaughnessy JA (2003) Pegylated liposomal doxorubicin in the treatment of breast cancer. Clin Breast Cancer 4: 318-328

Pai VB, Nahata MC (2000) Cardiotoxicity of chemotherapeutic agents: incidence, treatment and prevention. Drug Saf 22: 263-302

Ranson MR, Carmichael J, O'Byrne K, Stewart S, Smith D, Howell A (1997) Treatment of advanced breast cancer with sterically stabilized liposomal doxorubicin: results of a multicenter phase II trial. J Clin Oncol 15: $3185-3191$

Singal PK, Iliskovic N (1998) Doxorubicin-induced cardiomyopathy. N Engl J Med 339: $900-905$

Symon Z, Peyser A, Tzemach D, Lyass O, Sucher E, Shezen E, Gabizon A (2000) Selective delivery of doxorubicin to patients with breast carcinoma metastases by stealth liposomes. Cancer 86: 72-78

Theodoulou M, Hudis C (2004) Cardiac profiles of liposomal anthracyclines. Cancer 100: 2052-2063

Von Minckwitz G, Jonat W, Fasching P, du Bois A, Kleeberg U, Luck HJ, Kettner E, Hilfrich J, Eiermann W, Torode J, Schneeweiss A (2005) A multicentre phase II study on gefitinib in taxane- and anthracycline-pretreated metastatic breast cancer. Breast Cancer Res Treat 89: $165-172$

Katholisches Krankenhaus 'St Nepomuk', Erfurt, Germany (Christina Müller, MD); St Marien Krankenhaus Hamm, Hamm, Germany (Heinz Dürk, MD); St Vincentius-Klinik Karlsruhe, Karlsruhe, Germany (Hans-Gerd Meerpohl, MD); Universitätsklinikum Bonn, Bonn, Germany (Thomas Bauknecht, MD); Klinikum Chemnitz, Chemnitz, Germany (Klaus Renziehausen, MD); Onkologische Praxis, Ingolstadt, Germany (Peter Maubach, MD); Universitäts-Frauenklinik Tübingen, Tübingen, Germany (Diethelm Wallwiener, MD); Frauenklinik der Universität Ulm, Ulm, Germany (Rolf Kreienberg, MD); Dr-Horst-Schmidt-Kliniken, Wiesbaden, Germany (Andreas du Bois, MD); Klinikum St Marien, Amberg, Germany (Anton Scharl, MD); Universitätsklinikum 
Hamburg-Eppendorf, Hamburg, Germany (Fritz Jänicke, MD); Onkologische Praxis, Hamburg, Germany (Andreas Kopp, MD); Hämato-Onkologische Schwerpunktpraxis, Augsburg, Germany (Bernhard Heinrich, MD); Onkologische Gemeinschaftspraxis, Halle, Germany (Robert Rohrberg, MD); Martin-Luther-Universität Halle-Wittenberg, Halle, Germany (Heinz Kölbl, MD);

Universitätsklinikum Homburg/Saar, Homburg/Saar, Germany (Werner Schmidt, MD); Städtische Kliniken Oldenburg, Oldenburg, Germany (Hans J. Illiger, MD); Klinikum Quedlinburg, Quedlinburg, Germany (Otto Boldt, MD); Ammerland Klinik, Westerstede, Germany (Karl Werner Schweppe, MD); Universitätsspital Zürich, Zürich, Switzerland (Alexander Knuth, MD). 